\title{
THE LIFE HISTORY AND GENETIC SYSTEM OF LEUCOPOGON JUNIPERINUS
}

\author{
S. SMITH-WHITE \\ Botany Department, University of Sydney
}

\section{INTRODUCTION}

Received I9.v.54

Leucopogon juniperinus $\mathrm{R}$. Br. has a wide but apparently discontinuous distribution in the coastal and tableland regions of eastern Australia. It extends over a latitudinal range of nearly rooo miles, from Gympie (Queensland) to Gippsland, and is found at altitudes from sea level to 4000 feet. Throughout this range, the species shows a high degree of uniformity in morphological characters, and it is apparent that this uniformity has a cytological basis.

Material has been examined from the following localities :-

Queensland : Mt. Coot-tha (4 plants).

N.S.W. : Ghatswood (3 plants), East Gordon (11), West Pymble (4), Lane Cove (7), Yagoona (3), Newport (2), Yadboro Greek (4), Milton (1), Wandanian (3), Wauchope (2), Tooloom (2).

Aceto-lacmoid squashes were used for the examination of mitosis in leaf and ovule tissue, and for meiosis in pollen mother cells. Dissection squash methods were used to supplement section techniques in the study of embryo-sac development, and proved more valuable for the determination of chromosome constitution in embryo sacs, embryos and endosperms. Pollen tub: development in styles was examined in longitudinal sections cut on a freezing microtome at $c a$. 100 microns, and stained either in iodine or in acid fuchsin. Pollen size measurements were made by the use of a planimeter on camera lucida drawings.

\section{OBSERVATIONS}

\section{(I) Chromosome constitution}

In the 46 plants examined, and in 22 embryos dissected from young seeds, the somatic chromosome number was twelve. The chromosomes are of approximately equal length, and in size are comparable with those of the 4 -series diploid species $L$. setiger, L. esquamatus and $L$. propinquus, rather than with the chromosomes of the 6-series diploid species $L$. ericoides and $L$. microphyllus (fig. $8 \mathrm{c}$ ).

Following mild cold treatment $\left(4^{-} 6^{\circ} \mathrm{C}\right.$. for 48 hours) an apparent banding of the chromosomes can be seen in late prophase (fig. $8 \mathrm{~A}, \mathrm{~B}$ ), suggesting the existence of heterochromatic segments in all chromosomes. It is also possible to identify two short chromosomes in somatic tissue. Similar stages in cold-treated endosperms show three short chromosomes, which must therefore be homologues of the pairing chromosome sets, and not individuals of the univalent set.

Meiosis in P.M.Cs. has been described previously (Smith-White, 1948b). At $\mathrm{I}-\mathrm{M}$, four bivalents and four univalents are regularly present. There is never any indication of even temporary association 
in prophase between the univalents, either by chiasmata or secondary attraction. The mechanism suggested by Catcheside (I950) to account for the polarised segregation of $\mathrm{B}$ chromosomes in Parthenium could not be operative in the present case.

\section{(2) The development of the pollen}

Pollen development after meiosis conforms with that usual in the Styphelieae (Smith-White, I948a). A migration of the microspore nuclei (fig. IA) results in initialiy unequal microspores (fig. IB, c). The small microspores survive for a time, and contribute to the deposition of cell wall (fig. ID), but probably never undergo any mitosis. They contain degenerate cytoplasm when the functional microspore is still uninucleate (fig. IE). The large microspore increases considerably in size, and becomes a binucleate pollen grain (fig. IF, G). Mature pollen is apparently single but strictly monad in nature.
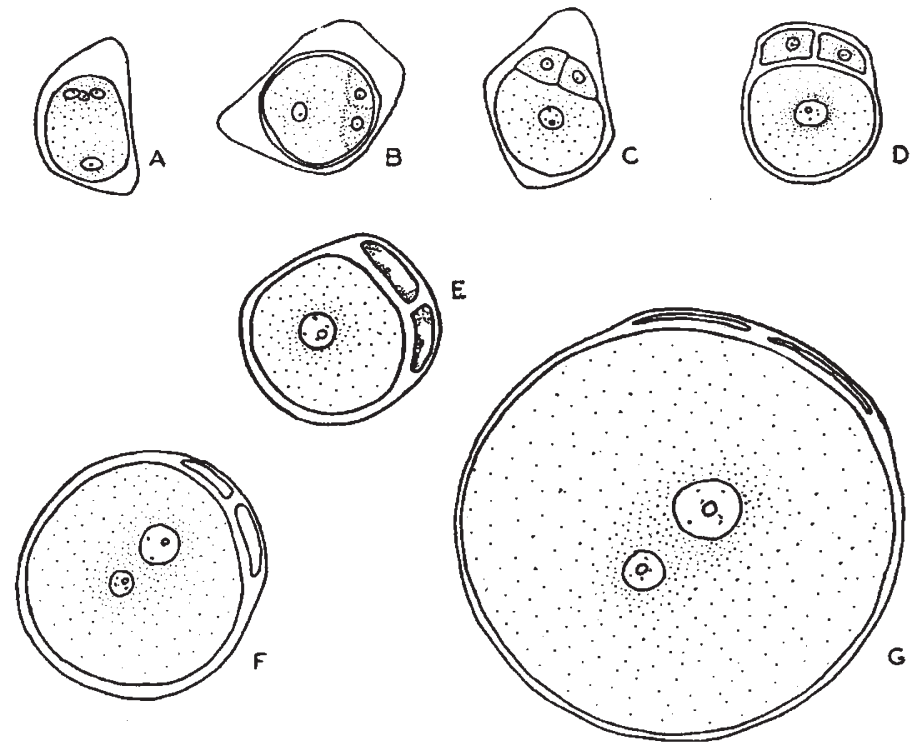

FIG. IA-G. $\times 640$. Pollen development in $L$. juniperinus.

A. Pollen mother cell following meiosis and nuclear migration.

B, C. Early stages in the development of the tetrad.

$\mathrm{D}, \mathrm{E}$. Uninucleate stages in pollen development.

F, A. A young binucleate pollen grain. The smaller nucleus, assumed to be the generative nucleus, is distal to the aborted cells.

G. The mature pollen grain.

This type of pollen development is found in most genera and species of the Styphelieae. It is characteristic of the tribe, and therefore antecedent to the condition of triploidy in L. juniperinus. A rather similar type of pollen development has been described in the Cyperaceae (Juel, I90o ; Stout, I912 ; Piech, 1928; Tanaka, 1940, I94I).

In the young pollen grain, the two nuclei are unequal in size and are asymmetrically placed. The smaller nucleus usually lies distally 
or obliquely to the aborted cells. If it may be assumed that the smaller nucleus is the generative one, this orientation does not conform to that characteristic of angiosperm pollen, as demonstrated by Darlington and Mather (1949) in Hyacinthus and by de Almeida and Sampaya (1950) in Luzula. Samuelsson (1913, cf. Maheshwari, 1950) reported that in Vaccinium the pollen tetrads produced their generative cells near the peripheral walls, but in tetrad pollen in Richea (fig. 3A, B) and in Epacris, the orientation of the generative nuclei is similar to that of Luzula.

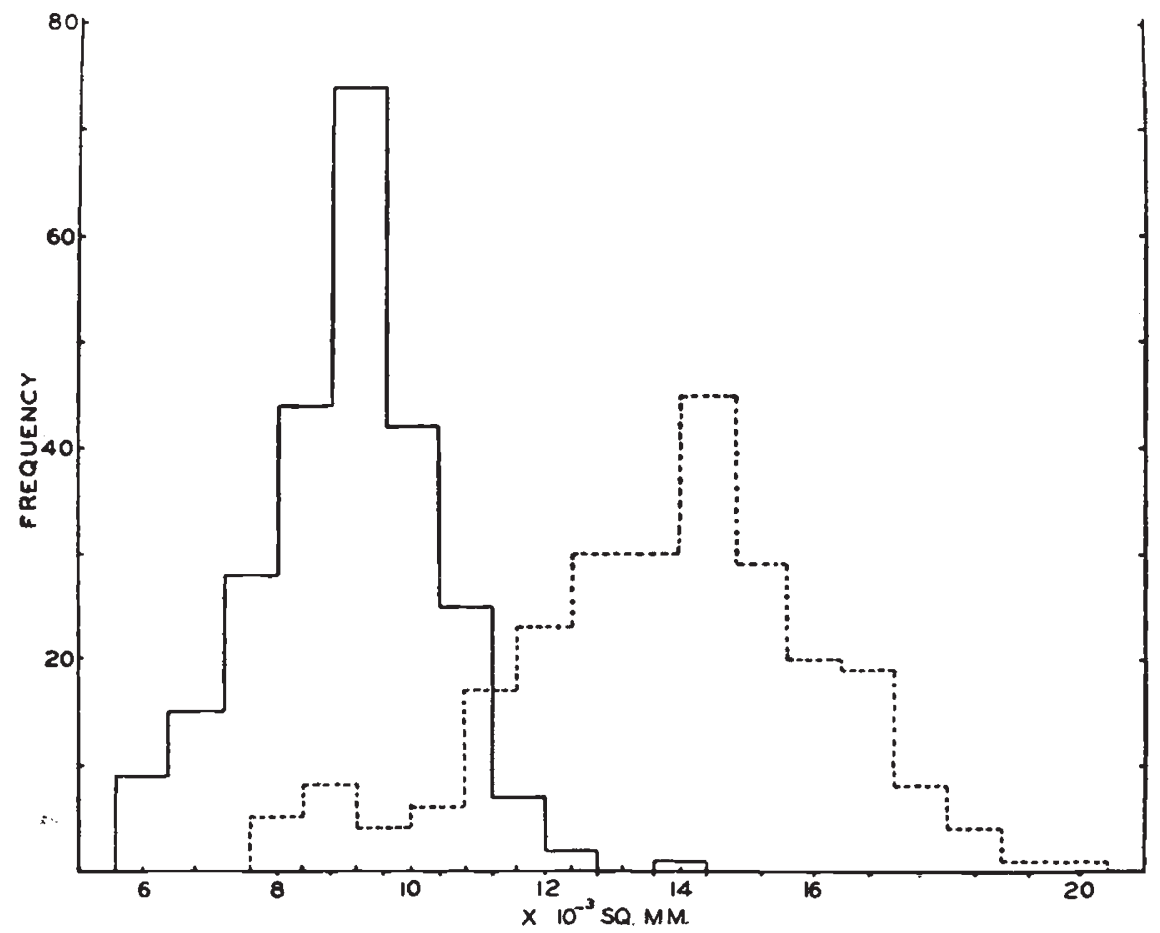

Fia. 2.-Pollen size distribution in $L$. juniperinus (dotted) and $L$. esquamatus.

The granular cytoplasm of the young pollen grain is densely packed with plastids and starch, and a direct determination of chromosome constitution in the P.G. mitosis has not been achieved. An analysis of variation in pollen size in comparison with that of the related diploid species $L$. esquamatus $(2 n=8)$ was made in an attempt to infer cytological heterogeneity (fig. 2). The pollen of $L$. juniperinus has a larger mean size, and a significantly higher standard deviation. However, both size distributions appear to be unimodal, and neither shows any significant deviation from normality. In $L$. esquamatus, the whole of the variability must be dependent upon differences in food storage, and in L. juniperinus, a similar explanation is probable. The data do not deny the view that the functional pollen is of uniform constitution. 
The extent of pollen fertility has been described previously (loc. cit.) where it was shown to be higher than would be expected with random univalent segregation. Culture of pollen in 25-30 per cent. sucrose solution, using La Cour's cellophane square technique (Darlington and La Cour, I948) results in rather erratic germination after $4^{8}$ hours. No approach to Ioo per cent. germination of apparently sound pollen has been achieved, but there does not appear to be any correlation between germination and pollen size. It is unlikely that germination of all potentially functional pollen can be obtained in sucrose solution. The tube cytoplasm, like the pollen cytoplasm, is granular and contains a great deal of starch.

Following artificial self-pollination of excised flowers in 2 in. $\times I$ in. phials, pollen germination and pollen tube penetration of styles have been observed in twenty-four hours. On the plant, flowers are markedly protandrous, and self-pollination seems to occur frequently before the corolla opens.

The Styphelieae are particularly suited for the study of pollen tube growth in styles. As in the Ericaceae, the style is hollow, and the pollen tubes grow down a central canal. The heavy concentration of starch in the tubes gives them an appearance not shared by stylar tissues. Using section-crush techniques, pollen tubes have been seen in the lower parts of the styles, and penetrating the micropyles of ovules. It is unlikely that the species is apomictic.

\section{(3) Megasporogenesis and the embryo sac}

Brough (1924) has described the morphological development of the female gametophyte in Styphelia longifolia, and his studies will provide a basis for comparison in the following treatment. In $S$. longifolia, the monosporic, 8-nucleate embryo sac is derived from the micropylar megaspore. The other three megaspores do not degenerate until after fertilisation. The primary endosperm nucleus is formed by the fusion of two polar nuclei, and is consequently diploid. The addition of a haploid male nucleus gives a triploid endosperm. Brough's treatment was entirely morphological, but triploid endosperms associated with diploid embryos $\left(2 x=8,3^{x}=12\right)$ have been observed in S. longifolia, S. triflora, S. laeta, S. tubiflora, Leucopogon esquamatus, $L$. rotundifolius, $L$. propinquus and $L$. setiger (fig. $8 \mathrm{E}, \mathrm{F}$ ). These determinations confirm Brough's interpretation.

The pistil of $L$. juniperinus is composed of five fused carpels. It is differentiated into a 5-loculed ovary, a hollow style 7-10 $\mathrm{mm}$. long, and a small glandular stigma. In each locule there is a single anatropous ovule on an apical placenta. In the young ovule a single massive integument surrounds a small nucellus comprising only a single axial row of cells and a nucellar epidermis. The terminal cell of the axial row becomes the E.S.M.C. At the time of meiosis the nucellus is deeply embedded in the integument, and is connected to the external micropyle by a long narrow canal. 
Meiosis in the E.S.M.C.-The course of meiosis in the E.S.M.C. appears to be identical with that already described for the P.M.C. In late prophase and at first metaphase four bivalents and four univalents are present. The univalents lie off the plate, towards either or both poles (fig. 4A, B), and may be pushed almost to the extremities of the spindle. The observed univalent segregation (table I) seems to be compatible with polarisation, and less so with random segregation.
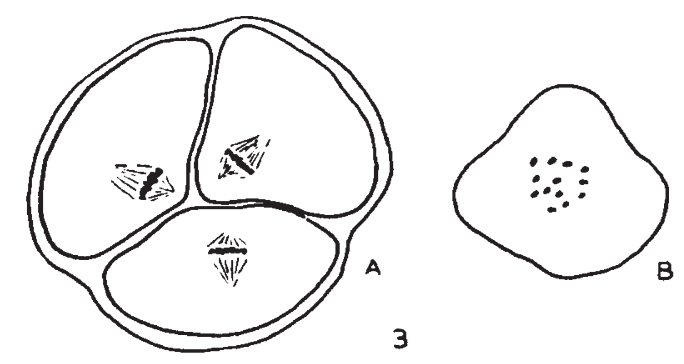

3

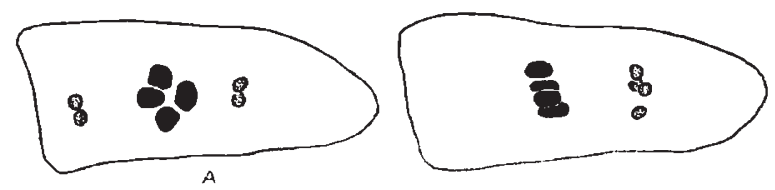

Figs. 3 and $4 . \quad \times 2080$.

FIG. 3A, B.-The pollen grain mitoses in tetrad pollen of Richea dracophylla (Epacridaceae, tribe Epacrideae). 3A eccentric spindles in the three pollen grains of the tetrad. $3^{B}$ Polar View of the metaphase plate in the fourth pollen grain of the same tetrad.

Fıg. 4A, B.-First metaphase in the E.S.M.C. in L. juniperinus. 4A A $2 / 2$ segregation of the univalents. $4 \mathrm{~B} \mathrm{~A} \mathrm{o/4} \mathrm{segregation} \mathrm{favouring} \mathrm{the} \mathrm{micropylar} \mathrm{pole.}$

Metaphase counts of the second division have not been obtained, but the divisions, seen in side view, are apparently normal, and a row of four megaspores is produced. The megaspores are at first of approximately equal size. There is no parallel to the nuclear migration found in the P.M.C.

TABLE I

Univalent distribution at $I-M$ in E.S.M.Cs. L. juniperinus

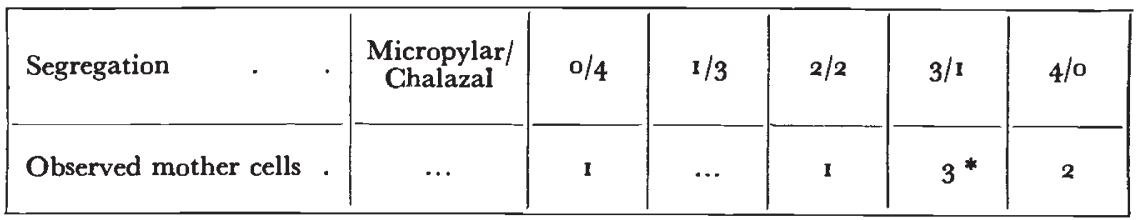

* In one of these cells, the distribution was actually $3 / 0$, with the fourth univalent lagging on the plate.

The development of the embryo sac.-The functional E.S. is always developed from the micropylar megaspore. It undergoes three mitoses to become 8-nucleate, and following the fusion of the polar nuclei, 7-nucleate. It contains an egg apparatus of two large terminally 
striate synergids and a large egg nucleus. There is a single endosperm nucleus and three small degenerate antipodal cells (fig. 5A-E). The three non-functional megaspores remain large and conspicuous even after fertilisation. Except for this feature, and for the selection of the micropylar megaspore, E.S. development conforms to the " normal" angiosperm type. Even where the micropylar megaspore fails, the others show no trace of development. There is no megaspore competition of the Oenothera muricata type.
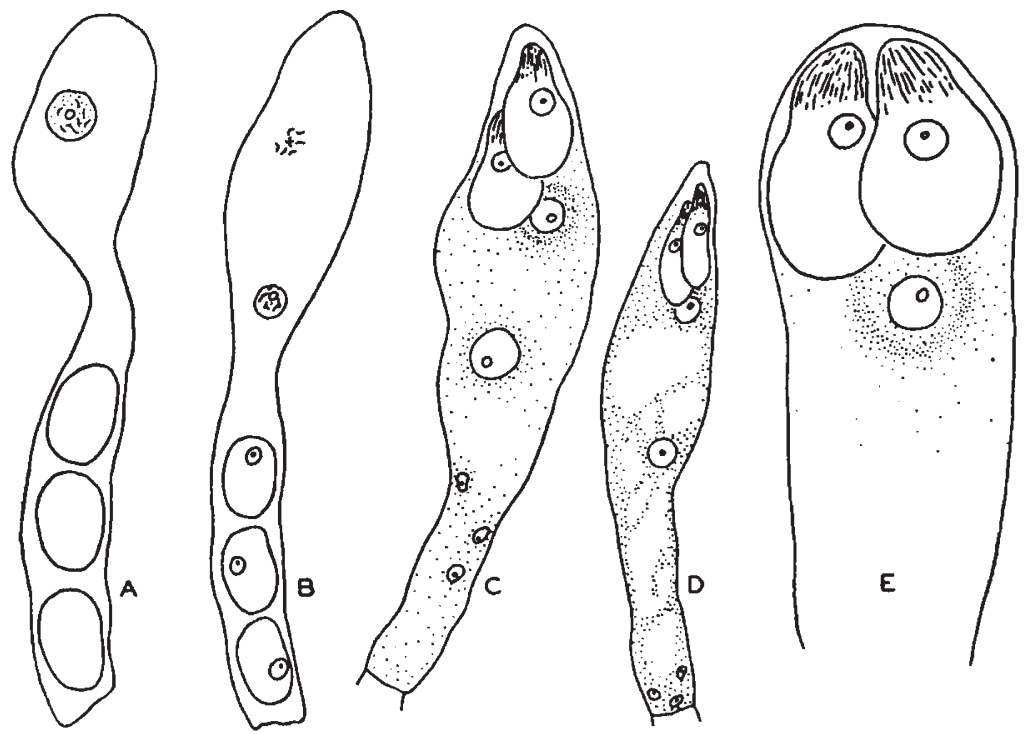

Fig. 5A-E. $\times 640$. Stages in embryo sac development in L. juniperinus.

A. The uninucleate embryo sac, with the three non-functional megaspores below. Lacmoid crush.

B. The second embryo sac division. Lower nucleus in late prophase, upper nucleus in metaphase, with eight chromosomes. Lacmoid crush.

c. The seven-nucleate embryo sac from a nearly mature ovule. The striate synergids are conspicuous, the other nuclei less so, and the sac is not obviously vacuolate. DissectionLacmoid.

D. A similar stage to 5 c. Paraffin section-Gentian Violet.

E. A fully mature embryo sac. Lacmoid-crush. The size of the sac has probably been influenced by flattening. The synergids are conspicuous.

Embryo sac abortion.-When all five embryo sacs in a nearly mature flower are examined, they rarely show comparable development (fig. 6). One, two, or more rarely three, may show "full" development, as judged by the presence of conspicuous synergids, and the others are underdeveloped. Observation of all five embryo sacs in a flower has been achieved in five cases (table 2). Pre-pollination E.S. abortion approximates to 75 per cent., and this frequency should be compared with data on seed fertility described below.

(4) The development of the seed

Pollination is necessary for fruit development, which has failed after emasculation of flowers on plants transferred to the garden. 
Stages in the development of the embryo and endosperm are illustrated in fig. 7A-C. The persistent endosperm is cellular. The
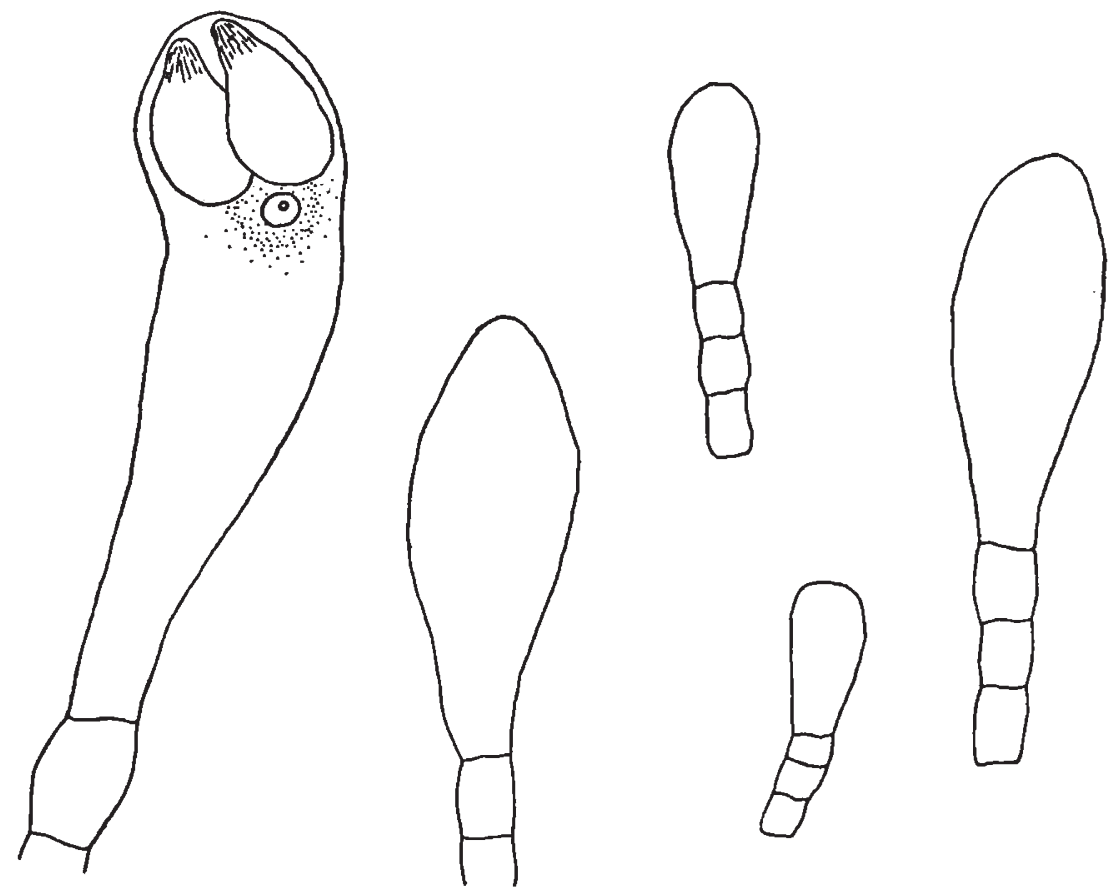

Fig. 6.-Outlines of the embryo sacs from the five ovules of a nearly mature flower bud. Only one is functional. In the other four the synergids are not developed, and they appear to have failed after partial growth. $\times 640$.

obsolete embryo sac can be recognised in stages later than that shown in fig. 7c. In that example two degenerate nuclei are shown in the

TABLE 2

Embryo sac fertility in L. juniperinus from East Gordon

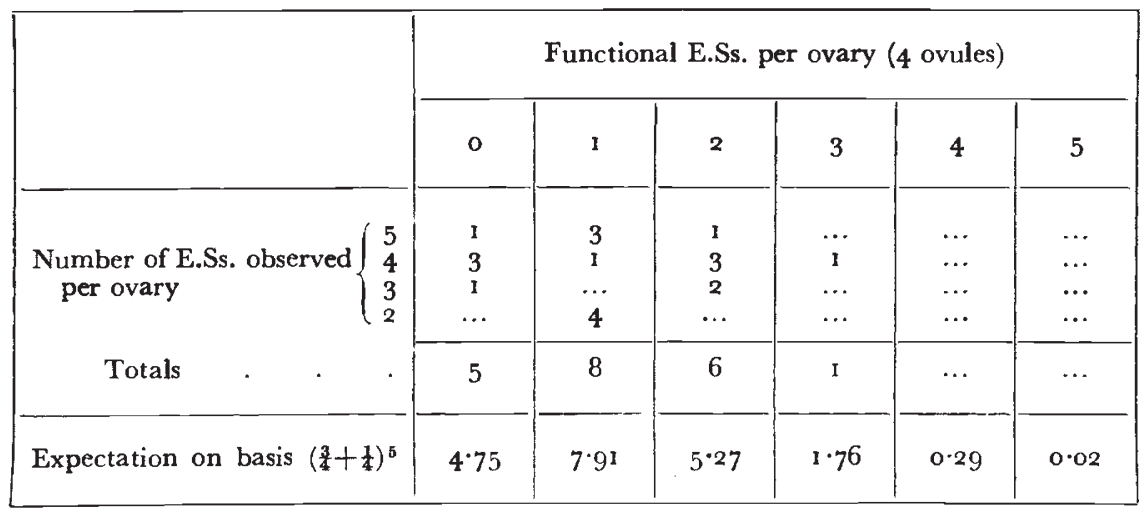

Embryo sac fertility :

(a) On assumption that E.Ss. not observed include functional and aborted in the same proportion .

(b) On assumption that embryo sacs not observed were undeveloped $23^{\circ} 0$ per cent. Fit to $\left(\xi+\frac{1}{4}\right)^{5}$ distribution, $\gamma^{2}=0.443$. 3 D.F. $\quad P=0.92$. 
lower half of the sac, and are probably two of the three antipodals ; the degenerate non-functional megaspores can still be recognised. The development is of the "caryophyllad" type as defined by Johansen (1950), and has a remarkable similarity to that of Medicago lupulina. A greatly elongated suspensor is apparently characteristic of the Styphelieae.
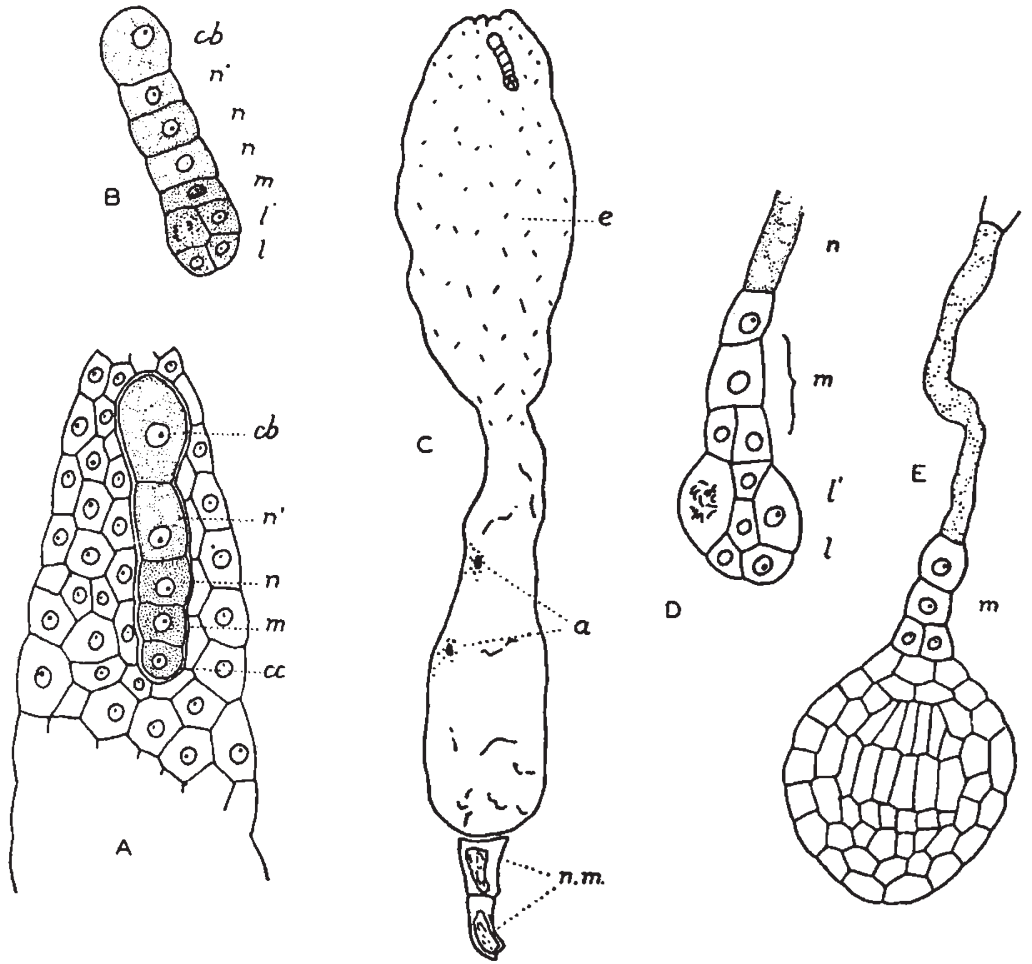

FrG. 7A-E.

Stages in embryo development in L. juniperinus

(notation following Johansen, I950).

A. A five-celled embryo. $c b$ and $n^{\prime}$ are differentiating, and possess vacuolate lightly staining cytoplasm. The whole of the embryo proper is derived from the cell $c c$. $\times 640$.

B. An embryo with a terminal octet $\left(l-l^{\prime}\right)$. These and cell $m$ appear to be the only ones which have not differentiated. $\times 640$.

c. The same embryo as fig. $7^{B}$ drawn at a lower magnification. The cellular endosperm (e) fills the upper half of the obsolete embryo sac. In the lower half two degenerate antipodal cells $(a)$ can be seen. The remnants of the nonfunctional megaspores $(n m)$ still persist. $\times$ r6o.

$D$, E. Later stages in the development of the embryo. The elongate cell of the suspensor is derived from $n$. $\times 640$.

Mitoses have been observed in embryos ranging in development from that illustrated in fig. 7A to that shown in fig. 7D. The chromosome complement is invariably 12 . Zygotic elimination of cytologically unbalanced embryos is not a factor of any importance in the stability of the species.

The endosperm is invariably pentaploid $(5 x=20)$. Counts have been obtained on 36 separate endosperms, including nine from which 
embryo counts were also obtained. Regular pentaploidy of the endosperm, associated with equally regular triploidy of the embryos, verifies the previous occurrence of double fertilisation, and is decisive in regard to the chromosome constitutions of the functional pollen grains and embryo sacs. The inference that only 4-chromosome pollen and 8-chromosome embryo sacs function is obligatory.
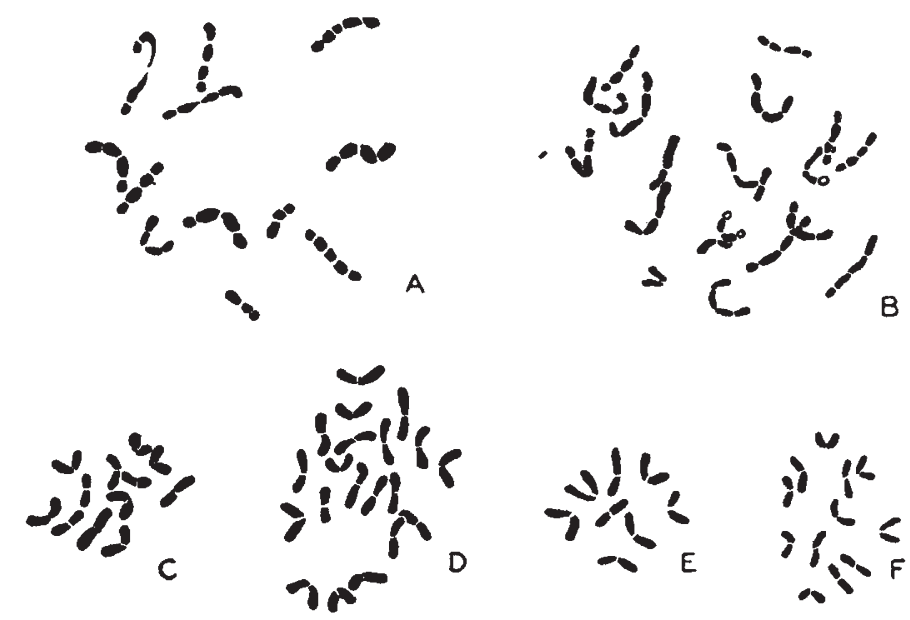

FiG. $8 \mathrm{~A}-\mathrm{F} . \times 2080$.

The somatic chromosomes of $L$. juniperinus (A-D) and L. rotundifolius $(\mathrm{E}, \mathrm{F})$.

A. Late prophase in an embryo, following cold treatment $3 x=12$.

B. Late prophase in endosperm, following cold treatment $5 x=20$.

C. Metaphase in embryo $3 x=12$.

D. Metaphase in endosperm $5 x=20$.

E. Metaphase in embryo $2 x=8$.

F. Metaphase in endosperm $3 x=12$.

Seed fertility.-L. juniperinus sets fruit abundantly. The proportion of fruit set, and seed fertility, can be estimated in a novel manner. Every ovary has five ovules, but fruits usually contain only one or two seeds. Data on number of seeds per fruit for $L$. juniperinus and other species are given in table 3. In the case of the East Gordon plants, the satisfactory fit of the observed distribution to the binomial $\left(\frac{3}{4}+\frac{1}{4}\right)^{5}$ indicates that only about 25 per cent. of ovules develop into seeds, that one functional seed serves to ensure fruit development, and that the fate of any ovule is independent of the fates of the other ovules in the same ovary. Further, it may be estimated that 25 per cent. of flowers fail owing to the absence of effective ovules.

In the Milton material, ovule fertility is much higher, exceeding 40 per cent., and approaches that found for the diploid species Styphelia tubiflora. The tetraploid L. biflorus has a lower fertility, approximately $12 \frac{1}{2}$ per cent. In all these examples, the observed distributions show a satisfactory fit with binomials. The data for L. setiger indicate a different basis of seed fertility, involving probably severe competition within the ovary. 
The data on pre-pollination embryo sac abortion were obtained from East Gordon plants. It is apparent that E.S. abortion is primarily responsible for seed failure, and this failure can in fact be recognised very early in the development of the fruit. With the evidence for polarised univalent segregation in meiosis and the requirement of an 8-chromosome embryo sac, it may reasonably be concluded that in 25 per cent. of the E.S.M.Cs. there is a full polarisation of the four univalents to the micropylar megaspore. Random segregation would give such an occurrence with a frequency of only $6 \frac{1}{4}$ per cent.

TABLE 3

Number of seeds per fruit in L. juniperinus and in related species

\begin{tabular}{|c|c|c|c|c|c|c|c|c|c|c|}
\hline \multirow{2}{*}{ Species } & \multirow{2}{*}{ Locality } & \multicolumn{6}{|c|}{ Fruits with seeds/fruit } & \multirow{2}{*}{$\begin{array}{l}\text { Total } \\
\text { fruits }\end{array}$} & \multirow{2}{*}{$x^{2}$} & \multirow{2}{*}{$\mathbf{P}$} \\
\hline & & $\mathbf{o}$ & I & 2 & 3 & 4 & 5 & & & \\
\hline $\begin{array}{l}\text { L. juniperinus } \\
\text { Binomial }(\cdot 75+\cdot 25)^{5} .\end{array}$ & $\begin{array}{c}\text { East } \\
\text { Gordon }\end{array}$ & $\ldots$ & $\begin{array}{l}183 \\
178 \cdot 9 x\end{array}$ & $\begin{array}{l}126 \\
I 19 \cdot 27\end{array}$ & $\begin{array}{l}29 \\
39 \cdot 76\end{array}$ & $6 \cdot 63$ & $\begin{array}{l}0 \\
0.44\end{array}$ & 345 & $34^{\circ}$ & 0.33 \\
\hline $\begin{array}{l}\text { L. juniperinus } \\
\text { Binomial }(\cdot 57+\cdot 43)^{5}\end{array}$ & Milton & $\dddot{48.85}$ & $\begin{array}{l}177 \\
184 \cdot 25\end{array}$ & $\begin{array}{l}28 \mathrm{I} \\
278 \cdot 00\end{array}$ & $\begin{array}{l}203 \\
209 \cdot 75\end{array}$ & $\begin{array}{l}94 \\
79 \cdot I 0\end{array}$ & $\begin{array}{l}8 \\
I I \cdot 93\end{array}$ & $7^{6} 3$ & $4 \cdot 64$ & 0.30 \\
\hline 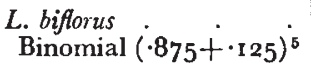 & Kosciusko & $\ldots$ & $\begin{array}{l}150 \\
{ }_{15} 0^{\circ} \cdot 43\end{array}$ & $\begin{array}{l}45 \\
4^{2} \cdot 98\end{array}$ & $\frac{5}{6} \cdot 14$ & $\begin{array}{l}0 \\
0 \cdot 44\end{array}$ & $\begin{array}{l}0 \\
0 \cdot O I\end{array}$ & 200 & $0 \cdot 4^{8}$ & $0 \cdot 78$ \\
\hline 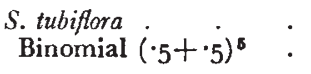 & Lane Gove & $\dddot{8}$ & $\begin{array}{l}4^{8} \\
4^{\circ}\end{array}$ & $\begin{array}{l}78 \\
80\end{array}$ & $\begin{array}{l}65 \\
80\end{array}$ & $\begin{array}{l}45 \\
40\end{array}$ & $\begin{array}{r}12 \\
8\end{array}$ & 248 & $7 \cdot 08$ & 0.14 \\
\hline L. setiger & Lane Cove & $\ldots$ & II6 & 8 & o & o & o & 124 & & \\
\hline
\end{tabular}

Note.-In calculation of $\chi^{2}$, classes with an expected frequency below 5 have been grouped with the next higher class.

In the P.M.C., where " ends" cannot be distinguished, polarisation results in only about 50 per cent. of viable monad pollen. The four univalents must pass to the same I-A pole in 50 per cent. of cases, or twice the frequency estimated for the E.S.M.Cs. If, however, in the E.S.M.G., polarisation is independent of the micropylar-chalazal axis, it could be inferred that in an additional 25 per cent. of E.S.M.Cs. all univalents would pass to the chalazal pole. The conditions of polarised segregation are probably similar in pollen mother cells and embryo sac mother cells.

\section{DISCUSSION}

Leucopogon juniperinus is a triploid, in which one haploid chromosome set shows no tendency to pair in meiosis. It must be allotriploid, with a diploid set from one parent and a haploid set from another. The morphological and cytological uniformity of the species, its wide and probably discontinuous range, and the absence of any obvious parental species, suggest that it has had a single and rather remote 
origin. It must have a rigid genetic system giving it little evolutionary potential.

In $L$. juniperinus neither apomixis nor zygotic selection can be operative. There is a system of complementary gametic elimination reminiscent of the inheritance of the rigens and curvans complexes in Oenothera muricata. Its genetic system extends that known in Rosa canina (Tackholm, 1922, Hurst, I93I). In both, the univalents are carried, apomictically as it were, in the maternal line only. In $L$. juniperinus, however, there is a controlled elimination of univalents in the pollen, and this condition is absent in $R$. canina. The origin of controlled univalent elimination in the pollen was probably dependent upon the prior existence of the monad type of pollen development, and on cytoplasmic polarity. It must be inferred also that in the E.S.M.C. the conditions for polarised segregation were antecedent to the origin of triploidy. Darlington's view (1937, p. 464) that in $R$. canina the control of univalent segregation in the E.S.M.C. was achieved by adaptation in the course of sexual reproduction cannot hold in the present case.

The systems of differentiation.-There are evidently several distinct sets of conditions operating in the development of the embryo sac in $L$. juniperinus, and these may be related to more normal conditions in the angiospermic ovule.

(I) There is a tissue gradient extending over the ovule, which determines the development of the micropylar megaspore. A similar gradient, more often favouring the chalazal megaspore, is normal in angiosperm ovules generally. There is no comparable condition in the anther.

(2) There is an intracellular gradient in the E.S.M.C., and also in the P.M.G., which controls univalent segregation. In the E.S.M.G., this gradient may act in either a micropylar or chalazal direction, and a functional E.S. is formed only when the two gradients act together. The tissue gradient is the stronger, since micropylar megaspores of unsatisfactory constitution show partial development, but chalazal ones never do so, even in the absence of effective micropylar competitors. This condition contrasts with that found in Oenothera muricata.

The control of P.M.C. and E.S.M.C. segregation must be similar, and in the former a source of polarity may be suggested in precocity of the normal polarity of the PG mitosis. If a similar gradient is normally present in the angiosperm embryo sac, it follows that the basic causes of differentiation in the pollen grain and embryo sac are in part related.

(3) An undefined set of conditions, different in anther and ovule, determines the development of the sporogenous tissue into microspores or megaspores, pollen grains or embryo sacs. The observations of Nemec, de Mol, Stow, and Naithani ( $c f$. Maheshwari, 1950) on the development of embryo-sac like pollen in Hyacinthus show that these conditions are basically independent of the gradients just defined. 


\section{SUMMARY}

I. Leucopogon juniperinus is a permanent triploid species with a somatic chromosome number of 12 . It has a wide distribution and is morphologically and cytologically uniform.

2. The species has retained a sexual system, and its stability as a permanent hybrid is maintained by complementary gametic elimination. Functional pollen is "haploid", and the univalents are excluded from paternal transmission. Functional embryo sacs are "diploid", and carry the univalents. There is a constant relationship of pentaploid endosperm with triploid embryos.

3. Conditions of meiosis are similar in the P.M.C. and E.S.M.C. In both, a similar intracellular polarity must control univalent segregation.

4. Pollen is of the monad type generally characteristic of the tribe Styphelieae. The conditions which determine monad development probably also control univalent segregation, and are certainly antecedent to the origin of triploidy.

5. In the embryo sac three conditions can be recognised as being involved in development and differentiation. The first is a tissue gradient in the ovule, which is not found in the anther. Second is the intracellular gradient which determines univalent segregation. Third is a set of conditions determining femaleness in development.

\section{LITERATURE CITED}

ALMEIDA, J. L. F., AND SAMPAYA, T. M. I950. Sobre a differenciacao nuclear nos microsporos de Luzula purpurea Link. Bol. Soc. Broteriana, 24, 323-332.

BRough, P. 1924. Studies in the Epacridaceae. i. The life history of Styphelia longifolia. Proc. Linn. Soc., N.S.W., 49, I62-1 78.

CATCheside, D. G. I950. The B-chromosomes of Parthenium argentatum. Genetica Iberica, 2, 1-10.

DaRlington, C. D. 1937. Recent Advances in Cytology. 2nd ed. Churchill, London. DARLINGTON, C. D., AND LA couR, L. F. 1948. The Handling of Chromosomes. 2nd ed. Allen and Unwin, London.

DARLINGTON, C. D., AND MATHER, K. 1949. The Elements of Genetics. Allen and Unwin, London.

HURST, c. c. I931. Embryo-sac formation in diploid and polyploid species of Roseæ. P.R.S., B, Iog, 126-1 28.

Johansen, P. A. 1950. Plant Embryology. Chronica Botanica Co., Waltham, Mass., U.S.A.

JUEL, H. O. 190o. Beitrage Zur Kenntnis der Tetradenteilung Jahrb. F. wiss. Bot., 35, 629-649.

MAheshwARI, P. 1950. An Introduction to the Embryology of the Angiosperms. McGrawHill, New York.

PIEch, K. 1928. Zytologische Studien an der Gattung Scirpus. Bull. Acad. Polon. Sci. et Lettr., B, pp. I-43.

SMITH-WHITE, s. I948a. A survey of chromosome numbers in the Epacridaceae. Proc. Linn. Soc., N.S.W., 73, 37-56.

SMith-white, s. I948b. Polarised segregation in the pollen mother cells of a stable triploid. Heredity, 2, I 19-1 29. 
stour, A. B. 1912. The individuality of the chromosomes and their serial arrangements in Carex aquatilis. Arch.f. Zellforsch., 9, I I4-1 $4^{\circ}$. Cited from Maheshwari. 1950.

tackholm, G. 1922. Zytologische Studien uber die Gattung Rosa. Acta. Hort. Berg., 7, 97-381.

tanaka, N. 1940. Chromosome studies in the Cyperaceae VI. Pollen development and additional evidence for the compound chromosome in Scirpus lacustris L. Cytologia, Io, 348-362.

tanaka, N. 1941. Chromosome studies in the Cyperaceae XII. Pollen development in five genera, with special reference to Rhyncospora. Bot. Mag. (Tokyo), pp. $55^{-65}$. 